\title{
PELATIHAN PENULISAN PROPOSAL PROGRAM KREATIVITAS MAHASISWA (PKM) PADA PROGRAM STUDI PPKN IKIP PGRI PONTIANAK
}

\author{
Muhammad Anwar Rube'i ${ }^{1}$, Syarif Firmansyah', Yuliananingsih ${ }^{3}$, \\ Dada Suhaida ${ }^{4}$, Moad $^{5}$ \\ 1,2,3,4,5 Program Studi PPKn Fakultas Ilmu Pendidikan Dan Pengetahuan Sosial \\ IKIP PGRI Pontianak, Jalan Ampera No. 88 \\ 1e_mail: anwarptk87@gmail.com
}

\begin{abstract}
Abstrak
Tujuan kegiatan pengabdian adalah untuk memberikan pelatihan penulisan proposal program kreativitas mahasiswa untuk meningkatkan pengetahuan, pemahaman, dan keterampilan mahasiswa dalam menulis proposal PKM. Sasaran kegiatan adalah mahasiswa Program Studi PPKn sebanyak 50 orang. Pelaksanaan pengabdian di aula kampus ilham IKIP PGRI Pontianak. Metode pengabdian yang digunakan adalah ceramah, tanya jawab, diskusi, penugasan dan Pendampingan. Kegiatan pengabdian mulai dari tahap persiapan yakni observasi dan sosialisasi, sedangkan untuk pelaksanaan mulai dari penyajian materi, praktik, refleksi dan evaluasi. Hasil kegiatan pengabdian adalah (1) terdapat peningkatan kepecayaan, pemahaman dan pengetahuan terhadap proposal PKM 5 bidang yang ditawarkan oleh pemerintah melaui DRP2M; (2) kegiatan pengabdian masayarakat telah berhasil dilaksanakan dengan baik dan lancar, keberhasilan ini ditunjukkan dengan meningkatkanya pengetahuan dan keterampilan dalam menulis ide, judul, dan format proposal PKM sesuai 5 bidang; (3) meningkatknya pengetahuan dan keterampilan peserta menyusun proposal PKM dan mekanisme pengusulan proposal PKM; (4) peserta pelatihan telah menghasilkan produk berupa proposal PKM 5 Bidang.
\end{abstract}

Kata kunci : Proposal, Program Kreativitas Mahasiwa

\begin{abstract}
The purpose of community service activities is to provide training on writing proposals for student creativity programs to improve students' knowledge, understanding, and skills in writing PKM proposals. The target activity is 50 students of PPKn Study Program. Implementation of service in the ilham campus IKIP PGRI Pontianak hall. Service methods used are lectures, questions and answers, discussions, assignments and Assistance. Service activities start from the preparation stage, namely observation and socialization, while for the implementation starts from the presentation of material, practice, reflection and evaluation. The results of the community service activities are (1) there is an increase in trust, understanding and knowledge of PKM proposals 5 fields offered by the government through DRP2M; (2) community service activities have been successfully carried out well and smoothly, this success is demonstrated by improving the knowledge and skills in writing ideas, titles, and format of PKM proposals in accordance with 5 fields; (3) increased knowledge and skills of participants in preparing PKM proposals and the mechanism for proposing PKM proposals; (4) the training participants have produced a product in the form of a 5 Field PKM proposal.
\end{abstract}

Keywords: Proposal, Students Creativity Program 


\section{PENDAHULUAN}

Lulusan Perguruan Tinggi dituntut untuk memiliki academic knowledge, skill of thinking, management skill, dan communication skill. Kekurangan atas salah satu dari keempat keterampilan dan kemahiran tersebut dapat menyebabkan berkurangnya mutu lulusan. Sinergisme akan tercermin melalui kemampuan lulusan dalam kecepatan menemukan solusi atas persoalan yang dihadapinya. Perilaku dan pemikiran yang ditunjukkan akan bersifat konstruktif realistis, artinya kreatif (unik dan bermanfaat) serta dapat diwujudkan. Kemampuan berpikir dan bertindak kreatif pada hakekatnya dapat dilakukan setiap manusia apalagi yang menikmati pendidikan tinggi. Kreativitas merupakan penjelmaan integratif dari tiga faktor utama dalam diri manusia, yaitu: pikiran, perasaan, dan keterampilan. Dalam faktor pikiran terdapat imajinasi, persepsi dan nalar. Faktor perasaan terdiri dari emosi, estetika dan harmonisasi. Sedangkan faktor keterampilan mengandung bakat, faal tubuh dan pengalaman. Dengan demikian, agar mahasiswa dapat mencapai level kreatif, ketiga faktor termaksud diupayakan agar optimal dalam sebuah kegiatan yang diberi nama Program Kreativitas Mahasiswa (PKM).

PKM merupakan salah satu upaya yang dilakukan oleh Direktorat Riset dan Pengabdian Masyarakat (semula Direktorat Penelitian dan Pengabdian kepada Masyarakat Ditjen Dikti), Direktorat Jenderal Penguatan Riset dan Pengembangan, Kementerian Ristek Dikti untuk meningkatkan mutu peserta didik (mahasiswa) di Perguruan Tinggi agar kelak dapat menjadi anggota masyarakat yang memiliki kemampuan akademis dan/atau profesional yang dapat menerapkan, mengembangkan dan meyebarluaskan ilmu pengetahuan, teknologi dan/atau kesenian serta memperkaya budaya nasional. PKM dilaksanakan pertama kali pada tahun 2001, yaitu setelah dilaksanakannya program restrukturisasi di lingkungan Ditjen Dikti. Kegiatan pendidikan, penelitian dan pengabdian kepada masyarakat yang selama ini sarat dengan partisipasi aktif mahasiswa, diintegrasikan ke dalam satu wahana, yaitu PKM.

Program Kreativitas Mahasiswa (PKM) adalah suatu wadah yang dibentuk dalam memfasilitasi potensi yang dimiliki mahasiswa Indonesia untuk mengkaji, 
mengembangkan, dan menerapkan ilmu dan teknologi yang telah dipelajarinya di perkuliahan kepada masyarakat luas. PKM dikembangkan untuk mengantarkan mahasiswa mencapai taraf pencerahan kreativitas dan inovasi berlandaskan penguasaan sains dan teknologi serta keimanan yang tinggi. Dalam rangka mempersiapkan diri menjadi pemimpin yang cendekiawan, wirausahawan serta berjiwa mandiri dan arif, mahasiswa diberi peluang untuk mengimplementasikan kemampuan, keahlian, sikap, tanggungjawab, membangun kerjasama tim maupun mengembangkan kemandirian melalui kegiatan yang kreatif dalam bidang ilmu yang ditekuni.

Dengan demikian dapat disimpulkan bahwa Program kreativitas mahasiswa bertujuan untuk meningkatkan mutu lulusan perguruan tinggi agar kelak dapat menjadi anggota masyarakat yang memiliki kemampuan akademis yang dapat mengembangkan, menerapkan dan menyebarluaskan ilmu pengetahuan, teknologi maupun seni dan budaya Indonesia.

PKM secara umum bertujuan untuk meningkatkan iklim akademik yang kreatif, inovatif, visioner, solutif dan mandiri. Meningkatkan mutu peserta didik (mahasiswa) di Perguruan Tinggi agar kelak dapat menjadi anggota masyarakat yang memiliki kemampuan akademis dan/atau profesional yang dapat menerapkan, mengembangkan dan meyebarluaskan ilmu pengetahuan, teknologi dan/atau kesenian serta memperkaya budaya nasional

Urgensi dari PKM itu sendiri adalah sebagai wadah bagi mahasiswamahasiswi mengembangkan kreativitas intelektual dan kecerdasan dalam berorganisasi. Kreativitas merupakan paduan tiga unsur utama dalam diri manusia, yaitu: pikiran, perasaan, dan keterampilan. agar mahasiswa-mahasiswi mencapai level kreatif, ketiga unsur tersebut diupayakan di setiap perguruan tinggi. Upaya tersebut terwujud dalam program kreativitas mahasiswa (PKM). Kegiatan PKM ini bertujuan untuk menampung aspirasi mahasiswa, mewadahi kreatifitas mahasiswa, membuat mahasiswa untuk menciptakan suatu inovasi, membuat mahasiswa untuk meneliti penemuan terbaru mereka.

Maka dari itu, ini menjadi tugas penting bagi Perguruan tinggi, Khususnya IKIP PGRI Pontianak untuk memperhatikan pengembangan kemampuan dan 
kreativitas mahasiswa, tetapi perlu kerjasama dengan semua jajaran yang ada di kampus. Bagi para dosen pembimbing agar tidak hanya sekedar membimbing, tidak hanya sekedar tanda tangan, tapi perlu komitmen dengan tugasnya sebagai pembimbing generasi penerus bangsa melalui PKM. Para mahasiswa hendaknya selalu dibimbing agar berkembang secara memadai, dan tugas para dosen pembimbinglah yang membimbing mereka dengan baik.

Sementara, para mahasiswa disarankan untuk tidak menjadi seperti katak di dalam tempurung, tetapi berusaha untuk terbuka, mencoba untuk melihat dan mengambil kesempatan yang ada, serta mencoba untuk terlibat dengan kesempatan yang ditawarkan oleh kampus melalui PKM. Hal ini terlihat masih rendahnya minat dan motivasi mahasiswa Program Studi PPKn untuk membuat proposal PKM 5 Bidang yang di tawarkan oleh Direktorat Jenderal Penguatan Riset dan Pengembangan, Kementerian Ristek Dikti dalam setiap tahunnya. Mahasiswa PPKn masih belum pernah mengirimkan proposal dan berkompetisi secara langsung. Hasil wawancara dengan salah satu mahasiswa menyebutkan bahwa mereka sudah pernah membuatnya, namun tidak sampai selesai karena dianggap masih mengalami kesulitan terhadap pengetahuan dan keterampilan dalam menulis prposal PKM. Selanjutnya, hasil wawancara dengan dosen prodi PPKn menjelaskan bahwa Prodi PPKn sudah pernah memberikan pelatihan, namun tidak maksimal. Sehingga, menurut salah satu mahasiswa mengatakan bahwa pentingnya untuk mengadakan pelatihan secara terus-menerus terkait penulisan proposal PKM guna meningkatkan prestasi dan pengalaman mahasiswa selama perkuliahan. Diharapkan pelatihan tersebut dapat meningkatkan minat dan motivasi mahasiswa untuk menulis proposal PKM agar bisa lolos.

Menyadari hal tersebut maka Dosen Program Studi Pendidikan Pancasila dan Kewarganegeraan IKIP PGRI Pontianak merasa perlu menyelenggarakan pelatihan penulisan Proposal Program Kreatifitas Mahasiswa (PKM) untuk mahasiswa Program Studi PPKn yang nantinya akan menghasilkan proposal yang baik untuk siap berkompetisi di tingkat nasional. Tujuan dari Pelatihan penulisan proposal Program Kreatifitas Mahasiswa (PKM) adalah (1) meningkatkan pengetahuan dan pemahaman mahasiswa terhadap Propsal 7 bidang PKM; (2) 
meningkatkan motivasi dan kesadaran Mahasiswa Prodi PPKn untuk membuat proposal Program Kreatif (PKM); (3) meningkatkan kemampuan dan keterampilan mahasiswa dalam menulis Proposal PKM sesuai dengan panduan PKM.

Target yang ingin dicapai dalam kegiatan pengabdian ini adalah untuk meningkatkan pengetahuan, pemahaman dan kemampuan mahasiswa dalam membuat proposal Program Kreativitas Mahasiswa (PKM) yang menghasilkan produk proposal yang siap berkompetisi secara nasional. Sedangkan secara khusus, target yang ingin dicapai adalah (1) meningkatkan kreativitas, inovasi dan produktivitas mahasiswa dalam menghasilkan karya yang bernilai tinggi dan berdaya saing secara global; (2) membekali mahasiswa prodi PPKn dalam meningkatkan pengetahuan, wawasan dan kemampuan menulis proposal PKM yang sesuai dengan pedoman PKM Dikti; (3) mahasiswa Prodi PPKn Dapat menghasilkan proposal PKM yang siap berkompetisi nasional; (4) meningkatkan jumlah dan kualitas proposal yang diterima dan memenangkan 5 bidang tingkat Dikti untuk selanjutnya diikutkan dalam ajang PIMNAS 2018 pendanaan 2019; mendorong IKIP PGRI Pontianak untuk meningkatkan kemampuan mahasiswa IKIP PGRI Pontianak dalam mengembangkan kreativitas, inovasi dan produktivitas melalui kegiatan seminar dan workshop pelatihan Porogram kreativitas mahasiswa secara berkelanjutan dan mendatangkan narasumber dari pihak Kementerian Ristekdikti.

\section{METODE}

Kegiatan pengabdian berupa pelatihan penulisan proposal program kreativitas (PKM) untuk keningkatkan pengetahuan dan keterampilan mahasiswa dalam menulis proposal PKM yang baik. Khalayak sasaran kegiatan pengabdian adalah mahasiswa Program Studi PPKn Fakultas IPP IKIP PGRI Pontianak yang berjumlah 50 orang. Pelaksanaan kegiatan pengabdian di Aula Kampus Ilham IKIP PGRI Pontianak yang beralamat di Jalan Ilham Kota Baru Pontianak. Metode yang digunakan dalam kegiatan pengabdian ini adalah metode ceramah, diskusi, penugasan, dan tanya jawab. Penyelenggaraan kegiatan terdiri atas 
presentasi penyampaian materi dan diskusi yang dilanjutkan dengan pelatihan penulisan proposal PKM 5 bidang. Seminar diisi dengan dengan pemaparan materi pokok yang disampaikan oleh para narasumber yang akan menjelaskan substansi maeri-materi yang disampaikan berkenaan dengan program yang dibuat. Kemudian workshop dan pendampingan dalam penyusunan proposal PKM dan diskusi pasca penyampaian materi dan pada saat bedah (klinik).

\section{HASIL DAN PEMBAHASAN}

Pelatihan penulisan proposal PKM (Program Kreativitas Mahasiswa) ini dilaksanakan pada tanggal 21-22 September 2018 bertempat di ruang laboratorium PPKn, Kampus Ilham, dengan peserta terdiri dari 50 peserta mahasiswa. Materi pelatihan disampaikan oleh narasumber dari Program Studi Pendidikan Pancasila dan Kewarganegaraa, Fakultas Ilmu Pendidikan .dan Pengetahuan Sosial IKIP PGRI pontianak. Pelaksanaan pelatihan dilakukan selama dua hari, yaitu hari jumat dan Sabtu, Tanggal 21-22 September 2018, dengan urutan materi yaitu penyampaian materi "kiat-kita menulis ide proposal PKM, disampaikan oleh Bapak Sy. Firmansyah, M.Pd, penyampaian materi "Penulisan proposal PKM, disampaikan oleh bapak M. Anwar Rubei, M.Pd, Tutorial penulisan proposal PKM, dipandu oleh tim dosen prodi PPKn, praktik penulisan proposal dipandu oleh tim dosen prodi PPKn, pembahasan tugas peserta dan penilaian hasil latihan dipandu oleh tim dosen prodi PPKn dan dilanjutkan dengan diskusi dan tanya jawab.

Hasil kegiatan PPM yang telah dilaksanakan, diperoleh hasil yaitu: (1) kemauan dan motivasi peserta dalam menulis proposal PKM adalah cukup tinggi; (2) pemahaman peserta terhadap proposal PKM (program kreativitas mahasiswa) semakin menambah; dan (3) pemahaman mahasiswa terhadap kiat-kiat sukses menulis proposal PKM semakin bertambah; (4) kemampuan dan keterampilan mahasiswa dalam menulis dan membuat proposal PKM semakin bertambah; (5) meningkatnya jumlah proposal PKM yang dibuat oleh mahasiswa PPKn; (6) kualitas proposal PKM mahasiswa semakin baik untuk bisa lolos PIMNAS. 
Berdasarkan hasil temuan dari kegiatan pelatihan tersebut yang telah dilakukan, dapat diketahui bahwa program kegiatan pelatihan ini berjalan dengan lancar dan mencapai tujuan kegiatan. Indikatornya adalan bertambahnya pemahaman mahasiswa dalam menulis ide, judul, memilih bidang-bidang PKM, menulis proposal sesuai dengan aturan yang ditetapkan serta mengetahui prosedur dan langka-langkah dalam mengirim proposal. Peserta sangat antusias dalam mengikuti kegiatan pelatihan ini. Hal ini dapat diketahui dari banyaknya pertanyaan yang diajukan oleh peserta pada saat kegiatan pendampingan.

Pada saat penyampaian materi, banyak peserta yang mengajukan pertanyaan terkait beberapa hal, yaitu; (1) bagaimana membuat ide kreatis dan judul yang menarik sehingga bisa lolos PIMNAS; (2) bagaimana membuat latar belakang yang baik dan benar dalam proposal PKM; (3) bagaimana membuat proposal PKM sesuai dengan bidang-bidang PKM; (4) Bagaimana prosedur atau mekanisme dalam mengirim proposal PKM; (5) bagaimana proposal PKM bisa lolos.

Selama ini mahasiswa hanya tahu informasi penerimaan proposal PKM dari mulut ke mulut saja, mahasiswa belum memiliki pedoman untuk menulis proposal PKM yang baik dan benar. Hal ini, bahwa mahasiswa belum memiliki semangat dan motivasi untuk menulis proposal PKM, karena mereka lebih sibuk dan asyik dengan tugas kuliah, dan hanya kuliah dan selebihnya tidak ada kegiatan lain.

Namun, masih ada sebagian mahasiswa yang memiliki minat dan tertarik menulis proposal PKM karena ingin memiliki pengalaman dan berprestasi selama kuliah di kampus. pelatihan dan diskusi rutin merupakan langkah yang baik harus dilakukan oleh dosen dan program studi PPKn meningkatkan kreativitas mahasiswa untuk menulis dan meningkatkan prestasinya.

Berdasarkan hasil yang dicapai selama proses pelatihan dan akhir kegiatan pelatihan yang meliputi keaktifan, antusiasme, dan kreativitas dalam menghasilkan proposal PKM yang sesuai bidang-bidang PKM, dapat dinyatakan bahwa kegiatan pelatihan yang telah dilakukan berhasil meningkatkan kreativitas mahasiswa untuk menulis proposal PKM untuk lolos PIMNAS. 
Adapun hasil yang diperoleh dari kegiatan pengabdian pada masyarakat dengan kegiatan pelatihan adalah: (1) meningkatnya motivasi dan minat mahasiswa untuk membuat proposal PKM; (2) meningkatnya pemahaman dan pengetahuan peserta terhadap proposal PKM (Program Kreativitas mahasiswa); meningkatnya wawasan dan pengetahuan mahasiswa terhadap cara menulis ide kreatif, judul menarik, bidang-bidang PKM, cara membuat proposal PKM yang baik dan benar, serta mekanisme pengusulan proposal; (4) meningkatnya keterampilan dan kemampuan mahasiswa menulis proposal PKM sesuai bidangbidang PKM; (5) meningkatknya jumlah proposal PKM yang sesuai dengan bidang-bidang PKM.

\section{PEMBAHASAN}

Secara keseluruhan dapat dikatakan bahwa program kegiatan PPM ini dapat diselenggarakan dengan baik yang ditandai dengan telah dapat dihasilkannya produk proposal dari beberapa bidang PKM dari peserta. Selama pelatihan berlangsung juga sangat terlihat antusiasme peserta untuk mengetahui banyak hal tentang PKM, bidang PKM, menulis ide dan judul yang menarik, dan membuat proposal sesuai format bidang PKM. Hal ini tercermin dalam banyaknya pertanyaan yang diajukan oleh para peserta. Pelaksanaan pelatihan di awali dengan kedatangan tim PPM ke kampus Ilham, tepatnya diruang Lab. PPKn pad selasa. Selanjutnya dilakukan kegiatan pembukaan acara pelatihan secara bersama antara tim pelaksana kegiatan PPM Prodi PPKn IKIP PGRI Pontianak. Setelah pembukaan, dilanjutkan dengan sesi 1 penyampaian materi pertama yaitu kiat menulis ide dan judul menarik.

Materi pertama yaitu menulis ide dan judul yang menarik, yang disampaikan oleh Sy. Firmansyah, M.Pd. pada pertemuan tersebut, beliau menyampaikan bahwa biasanya hal yang paling pertama dilihat oleh evaluator pada proporsal PKM adalah judul dan topik PKM yang diajukan. Oleh sebab itu, usahakan judul yang diajukan dibuat semenarik mungkin. Jika dibandingkan antara dua judul berikut "Pembuatan bahan dasar kosmetik dari mentimun dan bengkuang" dan "Pembuatan bahan dasar kosmetik dari feces dan urine sapi", 
tentunya judul kedua lebih aneh dan menarik. Tentu saja judul yang menarik saja tidak menjamin proporsal tersebut pasti lolos.

Penyusun proporsal harus dapat menyakinkan evaluator bahwa dengan berbekal pengetahuan yang sudah ada (tercermin dari tinjauan pustaka), metode pelaksanaannya (tercermin pada materi dan metode), serta keberhasilan pelaksanaannya (tercermin pada penjadwalan dan pembiayaanya), ide yang tercantum pada judul proporsal tersebut dapat terealisasikan dengan baik. Sering juga evaluator menghadapi suatu kenyataan bahwa banyak proprorsal yang judulnya sangat menarik, akan tetapi ternyata setelah dibaca isi proporsalnya tidak mencerminkan dan mendukung judul tersebut, akibatnya evaluator tidak meloloskan proporsal tersebut.

Menurut narasumber, bahwa menulis ide kreatif dan menarik sebagai berikut: (1) update informasi. Salah satu kriteria penilaian yang akan dipertimabngkan bahwa proposalmu layak didanai atau tidak adalah keterbaruan tema yang akan diajukan, (2) tulis Porporsal sesuai dengan panduan. penulis proporsal sesuai dengan format yang diminta oleh pihak DIKTI merupakan suatu keharusan, (3) konsultasikan proporsal dengan pakarnya. Mencari pembimbing tersebut sudah terbiasa dan memiliki kemampuan yang memadai untuk meningkatkan motivasi, menajamkan serta membungkus ide dari mahasiswa untuk menjadi proporsal yang menarik, (4) bentuklah kelompok yang memiliki pengetahuan yang menunjang. Pembentukan kelompok penyusun proporsal akan sangat menentukan keberhasilan suatu prorsal, (5) pelajari kriteria penolakan. (6) Rancangan dana harus realistis. (7) tawarkan program yang aplikatif. Teori tentang segala ilmu pengetahuan memang sangat penting untuk dipelajari, namun sangat perlu untuk menggali solusi yang aplikatif. Banyak sekali proposalproposal yang memiliki tema aplikatif yang lolos ke PIMNAS.

Selanjutnya, materi kedua yaitu disampaikan oleh bapak M. Anwar Rubei, M.Pd dengan tema "Penulisan Proposal PKM 5 bidang". Adapun hal yang disampikan adalah terkait format penulisan PKM 5 bidang, mekanisme penulisan dan mekanisme pengusulan proposal agar lolos PIMNAS. Program Kreativitas Mahasiswa (PKM) diluncurkan oleh DP2M DIKTI dengan tujuan untuk 
mempersiapkan mahasiswa menjadi pemimpin yang mandiri dan arif. Dalam hal ini mahasiswa diberi kesempatan untuk mengimplementasikan kemampuan, keahlian, sikap tanggung jawab, membangun kerjasama tim maupun mengembangkan kemandiriannya melalui kegiatan yang kreatif dalam bidang ilmunya masing-masing.

Program-program PKM-P, PKM-T, PKM-M, PKM-K dan PKM-GT yang telah lolos seleksi, dievaluasi pelaksanaannya dan dinyatakan layak akan diundang ke Pekan Ilmiah Nasional (PIMNAS) untuk dievaluasi lebih lanjut. Khusus untuk PKM-AI tidak diikutsertakan dalam PIMNAS, akan tetapi bagi kelompok PKM-AI yang dinyatakan lolos seleksi akan diberikan pengharggan dalam bentuk insentif sebesar Rp. 3 juta dan karyanya diterbitkan di Jurnal Kreativitas Mahasiswa.

Tahapan proses diawali dengan penyiapan proposal PKM oleh mahasiswa bersama dosen pendamping. Seorang mahasiswa hanya diperbolehkan mengajukan maksimum dua proposal dengan ketentuan, menjadi ketua di satu proposal PKM 5 bidang dan/atau menjadi anggota di proposal PKM yang lain (5 (lima) bidang). Maksimum dua proposal juga berlaku untuk PKMKT (sebagai ketua dan anggota, atau keduanya sebagai anggota). Pembimbing hanya diperbolehkan membimbing maksimal 10 (sepuluh) proposal hibah di semua jenis PKM (PKM 5 (lima) bidang dan PKMKT). Tahap selanjutnya adalah mengajukan proposal ke Direktorat secara online dengan cara mengisi identitas pengusul dan mengunggah proposal ke SIM-LITABMAS (simlitabmas.dikti.go.id) oleh operator bidang kemahasiswaan di masing-masing Perguruan Tinggi asal mahasiswa. Selanjutnya, mahasiswa melengkapi identitas dan mengunggah proposal setelah mendapatkan username dan password dari Operator (Lembaga Kemahasiswaan) melalui email.

Dari segi cakupan materi, secara umum peserta menyatakan bahwa materi yang disajikan memadai dan sesuai dengan harapan mereka, yaitu dapat memahami urgensi PKM, menulis ide kreatif dan judul menarik, menulis proposal sesuai 5 bidang PKM, dan mekanisme pengusulan proposal PKM. Hasil akhir dari presentasi materi dan workshop menunjukkan adanya perubahan yang cukup 
berarti dalam hal wawasan tentang PKM. Dosen melakukan pembimbingan kepada mahasiswa dalam membuat proposal PKM sesuai bidang yang dipilih.

Berdasarkan hasil kegiatan dan pembahasan dapat disimpulkan bahwa: (1) kegiatan pengabdian masayarakat berupa pelatihan penulisan proposal PKM bagi mahasiswa telah berhasil dilaksanakan dengan baik dan lancar; dan (2) keberhasilan ini ditunjukkan dengan peserta pelatihan dapat menjelaskan pengetahuan tentang pengertian Program PKM dan 5 bidang proposal PKM; format penulisan proposal dan kiat-kiat lolos proposal (3) Meningkatnya keterampilan dan kemampuan peserta dalam membuat proposal PKM; (5) Peserta menghasil produk berupa proposal PKM sesuai bidang yang dipilih, yang siap untuk diajukan/diusulkan.

Adapun hasil kegiatan PPM ini jika mengacu pada tujuan PPM yang dibuat sebelumnya, maka dapat di deskripsikan sebagai berikut: (1) engetahuan dan Pemahaman Mahasiswa terhadap Proposal PKM. Hasil pelatihan yang telah dilaksanakan sebelumnya, menunjukkan bahwa tingkat pengetahuan dan pemahaman mahasiswa terhadap Proposal PKM dan panduan PKM sudah meningkat. Hal ini dapat di lihat pada saat mereka mendengarkan, bertanya dan mengerjakan tugas membuat proposal PKM sudah sesuai dengan apa yang disampaikan oleh pemateri. Mahasiswa sangat antusias dan semangat dalam mengikuti kegiatan workshop, hal ini terlihat dari banyaknya mahasiswa yang bertanya kepada para pemateri. Mahasiswa sudah mengetahui dan memahami seperti PKM, panduan PKM, cara membuat judul yang kreatif, cara menulis proposal sesuai dengan format penulisan dan sampai pada tahap mengerjakan tugas kelompok.

(2) Motivasi dan kesadaran pentingnya menulis Proposal PKM.Dari hasil kegiatan PPM menunjukkan bahwa motivasi mahasiswa untuk menulis proposal PKM semakin meningkat. Hal ini ditunjukkan dengan antusiasme dan semangat mereka untuk bertanya, mencatat dan mengerjakan tugas kelompok. Mahasiswa mulai menyadari bahwa tugas mahasiswa bukan hanya kuliah saja, akan tetapi perlu menciptakan kreatfitas dan inovatif dalam hidup. Mahasiswa perlu menulis proposal PKM agar bisa berhasil dan mendapatkan pengalaman berharga selama 
kuliah. Prestasi adalah sebuah kebanggan yang harus dicapai oleh setiap mahasiswa yang bisa diperoleh melalui program kreativitas mahasiswa. Mahasiswa sudah mulai sadar bahwa selain kuliah, perlu mencari ilmu dan pengalaman lain guna meningkatkan prestasi dan berkarya.

Kemampuan dan keterampilan menulis Proposal PKM. Hasil kegiatan PPM yang telah dilakukan menunjukkan bahwa terjadi peningkatan kemampuan dan keterampilan menulis Proposal PKM mahasiswa. Sebelum adanya pelatihan, mahasiswa masih belum mengetahui dan memahami secara baik bagaimana membuat proposal sesuai dengan panduan PKM. Mahasiswa sudah memiliki kemampuan dalam memahami PKM 7 bidang yang ditawarkan oleh kementerian. mahasiswa sudah memiliki kemampuan dalam mengalisa dan membuat judul sampai tahap lampiran-lampiran dalam membuat proposal. Mahasiswa sudah memahami dengan baik bagaimana membuat proposal yang baik dan bisa lolos. Selanjutnya, dari kegiatan PPM ini telah berhasil meningkatkan keterampilan mahasiswa menulis proposal PKM, hal ini dapat di lihat dari pemahaman dan kemampuan mahasiswa terhadap materi 7 bidang PKM. Hal lain menunjukkan bahwa mahasiswa sudah mampu membuat judul proposal sesuai 7 bidang PKM yang berbeda-beda. Yang tidak kalah pentingnya bahwa mahasiswa sudah mampu membuat proposal PKM sesuai dengan panduan PKM yang ada, dan sesuai dengan bidang-bidang PKM yang mereka pilih dalam kelompoknya.

\section{SIMPULAN}

Berdasarkan hasil kegiatan dan pembahasan, maka kegiatan pengabdian pada masyarakat yang telah dilaksanakan dalam bentuk pelatihan penulisan proposal PKM (Program Kreativitas Mahasiswa) dapat terlihat dari peningkatan perubahan kondisi pengetahuan, keterampilan, maupun sikap yang tampak pada peserta pelatihan, maka dapat disimpulkan bahwa: (1) Terdapat peningkatan kepecayaan, pemahaman dan pengetahuan terhadap proposal PKM 5 bidang yang ditawarkan oleh pemerintah melaui DRP2M; (2) Kegiatan pengabdian masayarakat telah berhasil dilaksanakan dengan baik dan lancar, keberhasilan ini ditunjukkan dengan meningkatkanya pengetahuan dan keterampilan dalam 
menulis ide, judul, dan format proposal PKM sesuai 5 bidang; (3) Meningkatknya pengetahuan dan keterampilan peserta menyusun proposal PKM dan mekanisme pengusulan proposal PKM; (4) Peserta pelatihan telah menghasilkan produk berupa proposal PKM 5 Bidang yang sesuai pilihan guna lolos PIMNAS 2019.

\section{UCAPAN TERIMA KASIH}

Terima kasih diucapkan kepada pihak mitra pengabdian kepada masyarakat yakni mahasiswa Program Studi Pendidikan Pancasila Dan Kewarganegaraan IKIP-PGRI Pontianak atas partisipasi dan kerja samanya. Serta lembaga institusi kampus IKIP PGRI Pontianak yang telah mendukung memberikan bantuan dana untuk kelancaran kegiatan pengabdian kepada masyarakat.

\section{DAFTAR PUSTAKA}

Direktorat Jenderal Pembelajaran Dan Kemahasisswaan. (2017). Pedoman Program Kreativitas Mahasiswa. Kemenristekdikti.

Direktorat Jenderal Pendidikan Tinggi Kemendikbud RI. 2013. Panduan Pelaksanaan Penelitian Dan Pengabdian Kepada Masyarakat Di Perguruan Tinggi Edisi IX Tahun 2013.

Lembaga Pengabdian Kepada Masyarakat. (2017). Buku Panduan Pelaksanaan Pengabdian Kepada Masyarakat. Pontinak. IKIP PGRI Pontianak.

Undang-undang Nomor 20 Tahun 2003 tentang Sistem Pendidikan Nasional. 